\section{Accidental Arytenoid Banding: An Unusual Complication of Single-Shot Ligation Therapy}

Multiple band ligators are usually preferred over single-shot devices for the eradication of esophageal varices [1,2]. However, a single-shot device is still used occasionally for the ligation of small numbers of remnant varices in the followup sections. This does not require placement of an overtube which has its own complications $[3,4]$.

A 63-year old man with Child-Pugh class C cryptogenic cirrhosis and an episode of esophageal variceal bleeding was admitted for eradication of varices. In the first session, ligation was performed with a multiple band ligator. In the second session, 1 week later, only a small varix was observed, and a single-shot device (Stigman-Goff endoscopic ligator, Bard Espana, Barcelona, Spain) was used without overtube.

The endoscope was inserted with the loaded band. In the esophagus, however, the band was not present on the tip of the endoscope, and it was thought that it had dropped off. The endoscope was withdrawn, reloaded, and inserted again. During this second attempt, the band was accidentally released in the pharynx and the arytenoid was ligated. The patient was immediately transferred to the otorhinolaryngology department and a band was withdrawn from the arytenoid. A control examination 24 hours later revealed that another band was still present in the arytenoid and mild bluish discoloration was noted (Figure 1). It was decided that the missing band from the first attempt actually ligated the arytenoid as well and that finally two bands had been present. The second band was gently withdrawn using a biopsy forceps. A control endoscopy 1 week later revealed ulceration on this area. It was confirmed 2 weeks later that the ulceration had healed without a scar (Figure 2) and the patient was perfectly well at a 2-month follow up.

Le Pena et al. have reported accidental arytenoid ligation without providing details about the outcome [2]. In our case, it was demonstrated that in such an accident, the band can easily be withdrawn, and even if it is left for more than 24 hours before

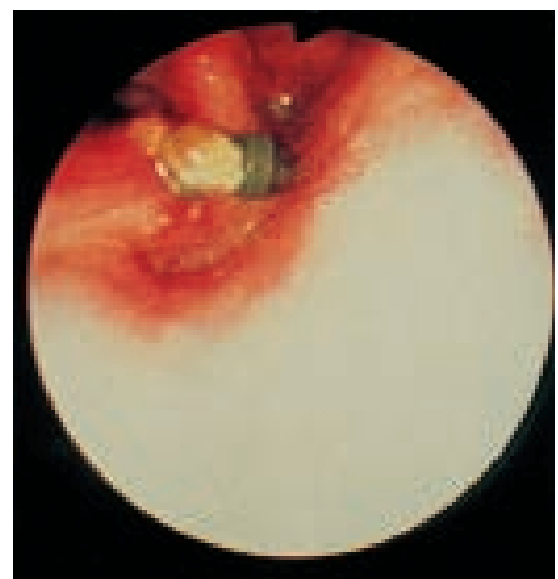

Figure 1 The endoscopic picture taken 24 hours after the incident reveals the presence of a band around the arytenoid with ulceration. This band was withdrawn using a biopsy forceps

withdrawal, serious consequences do not arise.

\author{
M. Akdogan ${ }^{1}$, E. Parlak ${ }^{1}$, A. Ülker ${ }^{1}$, \\ S.. Dagli ${ }^{2}$ \\ ${ }^{1}$ Dept. of Gastroenterology, \\ Türkiye Yüksek İhtisas Hospital, \\ Ankara, Turkey \\ 2 Dept. of Otorhinolaryngology, \\ Ankara Public Hospital, Ankara, Turkey
}

\section{References}

${ }^{1}$ Gilbert DA, Buelow RG, Chung RSK, et al. Technology assessment status evaluation: endoscopic band ligation of varices. Gastrointest Endosc 1991; 37: 670-672

2 de la Pena J, Rivero M, Sanchez E, et al. Variceal ligation compared with endoscopic sclerotherapy for variceal hemorrhage: prospective randomized trial. Gastrointest Endosc 1999; 49: 417-423

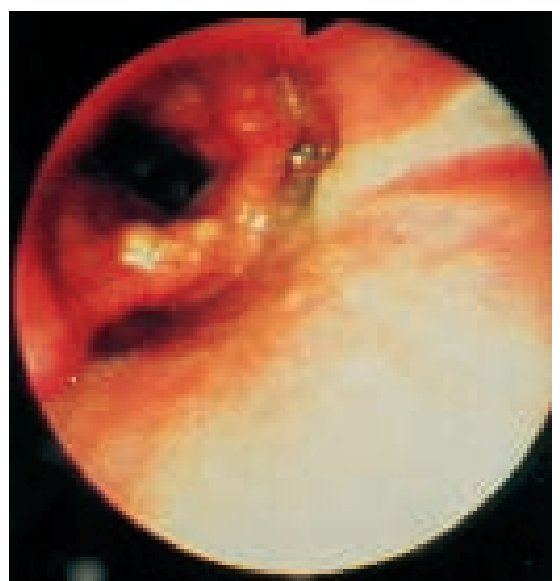

Figure 2 This picture, taken 2 weeks later, shows that the ulceration has seemingly healed without a scar

${ }^{3}$ El-Newihi HM, Mihas AA. Esophageal perforation as a complication of endoscopic overtube insertion. Am J Gastroenterol 1994; 89: 953-954

${ }^{4}$ Holderman WH, Etzkorn KP, Patel SA, Watkins JL. Endoscopic findings and overtube-related complications associated with esophageal variceal ligation. J Clin Gastroenterol 1995; 21: 91-94

Corresponding Author
M. Akdogan, M.D.
Bişkek Cd. (8.Cd) 65.Sok. İşçimen
Apt. 19/12
Emek
Ankara 06510
Turkey
Fax: +90-312-2156230
E-mail: akdmeral@yahoo.com

